\title{
COVID-19 Changed Human-Nature Interactions across Green Space Types: Evidence of Change in Multiple Types of Activities from the West Bank, Palestine
}

\author{
Emad B. Dawwas ${ }^{1, *}$ and Karen Dyson ${ }^{2}$ (D) \\ 1 Department of Urban Engineering Planning, An-Najah National University, Nablus P409, Palestine \\ 2 Dendrolytics, Seattle, WA 98105, USA; karenldyson@gmail.com \\ * Correspondence: dawwas@najah.edu
}

Citation: Dawwas, E.B.; Dyson, K. COVID-19 Changed Human-Nature Interactions across Green Space Types: Evidence of Change in Multiple Types of Activities from the West Bank, Palestine. Sustainability 2021, 13, 13831. https://doi.org/ $10.3390 /$ su132413831

Academic Editor: Richard Hauer

Received: 18 November 2021 Accepted: 12 December 2021 Published: 14 December 2021

Publisher's Note: MDPI stays neutral with regard to jurisdictional claims in published maps and institutional affiliations.

Copyright: (c) 2021 by the authors. Licensee MDPI, Basel, Switzerland. This article is an open access article distributed under the terms and conditions of the Creative Commons Attribution (CC BY) license (https:// creativecommons.org/licenses/by/ $4.0 /)$.

\begin{abstract}
COVID-19 stay-at-home orders impacted the way humans interacted with built and natural environments. Previous research on the human use of green spaces during the pandemic, largely conducted in a Western context, has found increased use of home gardens and urban green spaces, and decreased visitation to conservation areas. We explored changes in residents' outdoor natureassociated activities during the pandemic in the West Bank, Palestine. We used a web-based survey to ask residents about their passive, interactive, and extractive outdoor activities that take place in home gardens, urban parks, and natural areas. Overall, our 1278 respondents spent less time with family and friends and more time alone. We found differences in respondent's participation in activities both between green space types and between activity types. Participation in passive appreciation of nature activities increased for home gardens but decreased in urban parks and natural areas. Interactive activities, including cultivation, increased for all areas, while extractive activities stayed the same or decreased. Only in natural areas did respondents' demographics explain changes in activity participation rates after the pandemic. Residents' increased time alone raises concerns about mental health. The differences we observed in activity participation across green space types highlights the importance of looking across different types of natural spaces and different activities in the same setting, as well as examining non-Western settings.
\end{abstract}

Keywords: COVID-19; garden; urban park visitation; nature; human activities; poaching; wellbeing; exercise; gardening; Palestine

\section{Introduction}

In 2020, the rapid transmission of COVID-19 forced governments around the world to adopt partial or complete lockdowns and impose social distancing measures to flatten the infection curve [1]. Stay-at-home orders have affected the way we interact with the built and natural environment [2-6]. Our activities, including work, education, recreation, and shopping, have been changed in terms of when, where, and how they take place [7].

These restrictions on outdoor activities have significant direct and indirect impacts on social-ecological systems [6,8,9]. Due to reduced human travel, 2020 witnessed a remarkable decline in air pollutants including $\mathrm{PM}_{10}, \mathrm{PM}_{2.5}, \mathrm{NO}_{2}$, and $\mathrm{CO}_{2}(\mathrm{Bar} 2020$; Chitra et al., 2020; Sharma et al., 2020), water pollution $[4,6,9]$ as well as noise pollution $[4,10]$, and domestic waste [6]. Wildlife sightings have increased, and wildlife behaviors have changed, including higher nesting rates recorded for species such as leatherback sea turtles and changes in routines for urban birds $[4,6,11]$, while poaching rates decreased across multiple countries [12].

Restrictions on outdoor activities caused by lockdown measures have also raised concerns about the physical and psychological consequences of prolonged isolation [13]. Social isolation, such as the isolation imposed by lockdown measures, is associated with 
risks of anxiety, depression, and premature mortality, among others [14,15]. The COVID19 pandemic has resulted in negative psychological effects including post-traumatic stress symptoms, confusion, and anger [16]. In such extraordinary situations, nature functions as a source of resilience for sustaining ordinary quality of life and well-being [1]. As the emerging body of literature indicates, nature has been increasingly perceived as a refuge from quarantine and the corresponding mental and psychological consequences $[13,17,18]$.

The pandemic has underscored previous research showing how important home gardens are for urban residents' wellbeing [19-21]. Gardens are places for many passive activities, including relaxing, exercising, socializing, and other activities with positive mental and spiritual effects [18]. Residents' interactive relationships with their gardens, including growing food and raising livestock, increased during the pandemic [18,22-25]. During the pandemic, these activities were related to reduced psychopathological distress [13,23]. Gardening activities proved an important affordable supplemental food source, alleviating the fresh food supply crisis particularly in rural areas [24,26]. Depending on their configuration, gardens can also provide appropriate and important habitat and food resources for different taxonomic groups including birds [27,28], mammals [29] and insects [30,31].

Urban green spaces and parks have also been an important refuge during the pandemic. During the pandemic, researchers have found that park use increased when parks were open $[2,3,18,32-40]$ and residents reported that these spaces improved their mental health $[38,40]$. These spaces have long been known to provide humans with multiple ecosystem services in addition to wellness, including mental health $[7,13,22]$, climate regulation [41], and cultural benefits [42].

New groups of nature and green space visitors appeared during the pandemic, including non-locals, families with children, and young people [30]. However, residents' activities shifted during the pandemic, with foraging, gardening, hiking, jogging, relaxing alone, walking, interacting with wildlife, and photography and other art-related activities increasing [39,43] and camping and relaxing with others decreasing [39].

Research into natural areas has suggested that visitation to conservation areas decreased significantly in many countries (including Brazil, Costa Rica, Ecuador, Namibia, Indonesia, USA, and Canada, while Germany is an exception) [12,44]. Internationally, public interest in national parks as measured by internet search volume decreased during the COVID-19 pandemic, likely due to mobility restrictions and park closures [45]. As a result, multiple activities decreased, including hiking and camping, particularly in groups [39,46].

While these previous studies have uncovered significant changes in human-nature interactions wrought by the pandemic and lockdown, they focus on the outdoors generally [38] or on either national parks [5,44] or urban green space and parks (e.g., [2,3,40]). However, based on our review of previous research, outdoor activities-interactions between humans and nature-take place largely in three locations: (1) private green spaces, including home gardens; (2) public green spaces, including urban parks; and (3) natural areas. Likewise, residents' interactions with nature have three main modes: (1) passive relationships, in which people appreciate nature and perceive it as a place for healthy practices and wellbeing; (2) interactive relationships, in which people physically change components of nature without removing them, such as garden cultivation; and (3) extractive relationships, in which people harm nature by removing its components or negatively modifying them. All of these have not been combined in one study. Furthermore, most studies are of Western countries (e.g., [7,18,39,44]). A cross-sectional study asking residents how their patterns of use and behaviors changed across three distinct types of natural spaces is missing from the literature.

Here, we address this gap by surveying residents of Palestine, politically classified as an area of geopolitical conflict and socio-economically classified as a developing country, about their use of and activities in home gardens, urban green spaces and parks, and natural areas. We explore how the level of engagement in outdoor nature-associated activities has changed before and after the occurrence of the COVID-19 pandemic in the West Bank. We build on previous research by addressing new cultural contexts and multiple key locations 
of human interaction with nature to uncover how respondents may have shifted their behavior during the COVID-19 pandemic.

\section{Materials and Methods}

\subsection{The Study Area and Pandemic Context}

The West Bank is part of the Palestinian Occupied Territories (Figure 1). The area of the West Bank is $5628 \mathrm{~km}^{2}$ and is populated by 3.2 million people. About $60 \%$ of the population live in single-family housing, which is more likely to have a home garden and backyard, while $40 \%$ live in an apartment [47].

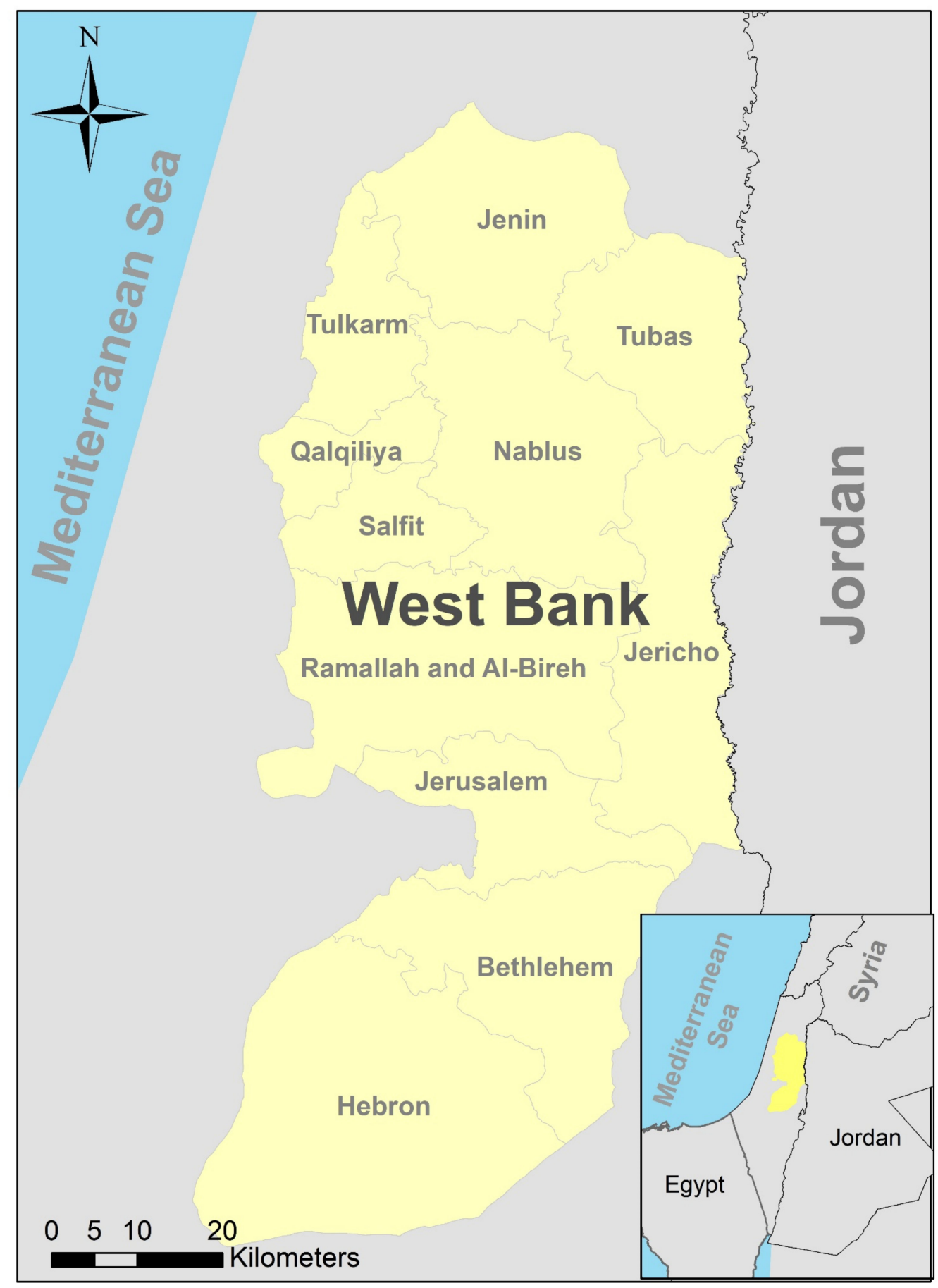

Figure 1. The Occupied Palestinian Territory West Bank study area including governorates. 
Green areas and urban parks in the West Bank have expanded significantly in the past decade. The number of urban green areas and parks within municipality boundaries has increased from 148 in 2009 to 233 in 2016 [48]. These areas constitute a range of recreational opportunities for Palestinians, including exercising, biking, picnicking, birdwatching and photography, providing a safe space for children to play, practicing amusement activities, and socializing and gathering.

Natural areas in Palestine colloquially include open spaces outside and around towns and cities, including national parks, woodlands and forests, mountains, hills and moorlands, countryside, farmland, springs, and streams. These natural open spaces include both public areas that cannot be modified or cultivated and private areas that can. Overall, 9 percent of the total area of the West Bank is now protected in 48 public natural reserves [49]. In the past decade, significant attention has been paid to natural and wilderness tourism and natural reservation and protection, and several groups and assemblies of nature exploration have been established [50]. On private lands, people may spend their time and money landscaping and cultivating them; that is, in enhancing the land for agriculture purposes by (1) changing the topography of the land, including by making agricultural terraces and water harvesting structures in sloped land; (2) planting fruitful trees, especially olive trees; or (3) cultivating field crops or irrigated agriculture.

On 5 March 2020, the first case of COVID-19 was discovered in the West Bank. A week later, the Palestinian government declared a state of emergency and imposed a complete lockdown on the West Bank to prevent the spread of the pandemic. Residents were restricted from going out, all governmental institutions and organizations were closed including schools, universities and ministries, and non-governmental and private sector establishments were also closed.

Over the following year, the lockdown continued, though with fluctuating levels of restrictions. The West Bank is divided into 11 administrative entities (governorates; Figure 1). Governorates with fewer cases experienced a limited intermittent easing of road closures and movement restrictions, while a significant tightening was imposed on the most affected governorates. This situation continued until the end of April 2021, when all movement restrictions were removed regardless of the number of cases in each governorate.

During this period, there was widespread confusion regarding whether the public was restricted from or encouraged to visit urban parks and natural open spaces. On one hand, there were unofficial advisories from the local health managers to the residents encouraging them to visit open natural areas and wilderness; these directives emphasized prevention measures. On the other hand, official communications from the central Palestinian government asked people to stay home without exceptions.

\subsection{Survey Design and Implementation}

Online surveys have been extensively used as a tool to collect data related to the COVID-19 pandemic and the lockdown, as they comply with distancing regulations and facilitate collecting data from more people easily and quickly [22,37-41,43,51,52].

We designed and implemented an online survey using Google Forms. We distributed the survey online via a sponsored Facebook ad. This approach is potentially biased in favor of respondents who have internet and Facebook accounts (though see Section 2.3); however, this effect is reduced as 55.2\% of Palestinians are Facebook users [53]. The ad ran for 10 days from 24 June to 4 July 2021, and it targeted adults over 18 years old who were living in the West Bank. All subjects gave their informed consent for inclusion before they participated in the study (Supplemental Information S1). The study was conducted in accordance with the Declaration of Helsinki. Residents were encouraged to participate and to share the questionnaire with more friends by offering a chance of having a gift of 100 NIS (30 USD), a kilogram of natural honey, or a free tour of the nature of Palestine.

The survey aimed to collect data about the level of engagement in outdoor natureassociated activities before and after the occurrence of the COVID-19 pandemic in the West 
Bank. We ensured participants understood the goal of the survey and any terms used by providing an introductory paragraph for the survey and for each section of the survey (Supplemental Information S1). As we intended to pose the survey for the public, we made sure that it could be completed within 5 to 7 minutes by testing it with 16 participants divided between experts and ordinary people.

The survey consisted of four sections (Figure 2). In the first section of the survey, we asked participants about their demographics including gender, age, income and employment, place of living and type of housing. The other three sections of the survey first asked a screening question and then asked additional questions about different activities taking place in home gardens, urban parks and green spaces, and natural spaces. The activities chosen were based on previous literature and personal experience of the researchers [37-39,52]. We used a five-point Likert scale to measure if respondents do that specific activity and if they engaged more, less or the same before and after the occurrence of the pandemic [22].

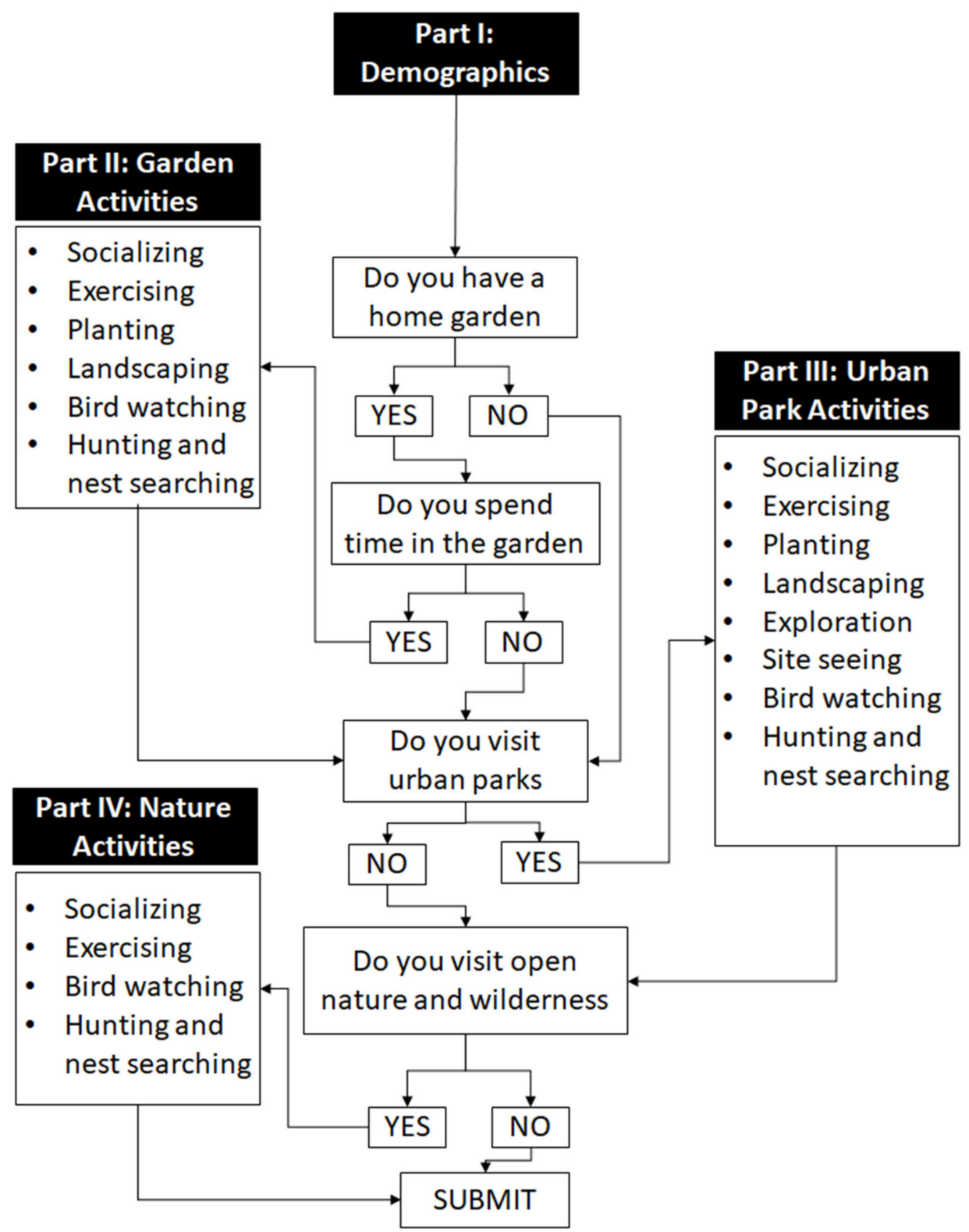

Figure 2. Logical chart of our survey instrument. The first part collected information on the demographics of all respondents, and the other three sections focused on the outdoor nature-associated activities. 


\subsection{Representativeness of the Sample}

Although the respondents in our sample were limited to those with Facebook accounts, most of the demographics are representative of the population of the West Bank (Table 1). Notable deviations include the number of female respondents at young ages (Supplemental Information S2). Additionally, demographic information for education was not found for the West Bank, but we suspect our sample may be more educated.

Table 1. Demographics of respondents compared with the West Bank (study population). Survey non-responses for each demographic question have been excluded for ease of comparison with the study population but are available in Supplemental Information S3.

\begin{tabular}{|c|c|c|c|c|}
\hline Demographic & Variable & Responses & $\%$ Sample & $\begin{array}{l}\text { \% West Bank } \\
\text { (Study Pop'n) }\end{array}$ \\
\hline \multirow{2}{*}{ Gender } & \multirow{2}{*}{$\begin{array}{c}\text { Male } \\
\text { Female }\end{array}$} & 591 & \multirow{2}{*}{$\begin{array}{l}46.4 \\
53.6\end{array}$} & 50.8 \\
\hline & & 683 & & 49.2 \\
\hline \multirow{3}{*}{ Marital status } & Single & 436 & 34.2 & 35.3 \\
\hline & \multirow{2}{*}{$\begin{array}{c}\text { Married } \\
\text { Other }\end{array}$} & 814 & 63.9 & 60.8 \\
\hline & & 24 & 1.9 & 4.9 \\
\hline \multirow{6}{*}{ Age group } & $18-25$ & 344 & 26.9 & 32.1 \\
\hline & $26-35$ & 358 & 28.0 & 25.7 \\
\hline & $36-45$ & 258 & 20.2 & 16.9 \\
\hline & $46-55$ & 198 & 15.5 & 11.8 \\
\hline & $56-65$ & 101 & 7.8 & 7.4 \\
\hline & Over 65 & 19 & 1.5 & 6.2 \\
\hline \multirow{2}{*}{ Housing type } & Apartment & 456 & \multirow{2}{*}{$\begin{array}{l}35.7 \\
64.3\end{array}$} & 40.0 \\
\hline & House & 820 & & 60.0 \\
\hline \multirow{4}{*}{ Place of living } & City & 636 & 49.9 & \\
\hline & Urban & 262 & 20.5 & 71.0 \\
\hline & Rural Village & 333 & \multirow{2}{*}{$\begin{array}{c}26.1 \\
3.5\end{array}$} & 24.0 \\
\hline & Refugee camp & 44 & & 5.0 \\
\hline \multirow{11}{*}{ Distribution bygovernorate } & Jerusalem & 126 & 10.0 & 15.1 \\
\hline & Jenin & 111 & 8.8 & 10.9 \\
\hline & Tubas & 53 & 4.2 & 2.1 \\
\hline & Tulkarem & 112 & 8.9 & 6.4 \\
\hline & Nablus & 197 & 15.6 & 13.3 \\
\hline & Qalqelyah & 68 & 5.4 & 3.9 \\
\hline & Salfit & 61 & 4.8 & 2.6 \\
\hline & Ramallah & 154 & 12.0 & 11.4 \\
\hline & Jericho & 9 & 0.7 & 1.7 \\
\hline & Bethlehem & 102 & 8.1 & 7.5 \\
\hline & Hebron & 272 & 21.6 & 25.1 \\
\hline Employment & Employed & 795 & 76.1 & 74.0 \\
\hline $\begin{array}{l}\text { For comparison, } 214 \text { students were } \\
\text { excluded from the calculations }\end{array}$ & Unemployed & 238 & 23.9 & 26.0 \\
\hline & Inside the West Bank & 927 & 90.0 & 86.9 \\
\hline Work location & Inside the Greenline & 103 & 10.0 & 13.1 \\
\hline & High School or Less & 187 & 14.7 & - \\
\hline & Bachelor & 755 & 59.5 & - \\
\hline Education & Diploma & 115 & 9.1 & - \\
\hline & Masters or more & 212 & 16.7 & - \\
\hline & Less than 2000 NIS & 136 & 11.8 & 14.0 \\
\hline & 2001-4000 NIS & 375 & 32.4 & - \\
\hline & 4001-6000 NIS & 196 & 17.0 & - \\
\hline Income before COVID-19 & 6001-8000 NIS & 64 & 5.5 & - \\
\hline & More than 8000 NIS & 59 & 5.1 & - \\
\hline & I have no income & 326 & 28.2 & - \\
\hline & I prefer not to answer & 104 & Excluded for comparison & - \\
\hline
\end{tabular}




\subsection{Statistical Analysis}

We received a total of 1316 responses. We removed responses with more than 5 (of 11) unanswered demographic questions, as well as any responses from respondents indicating they were less than 18 years old. This left us with a final total of 1278 responses.

We used the chi-squared goodness of fit test to test whether respondents' behavior changed after the COVID-19 pandemic. Our null hypothesis in all cases was that there had been no change, and that behavior before and after the pandemic was the same. Similarly, we used Pearson's chi-squared test to test for independence between the Likert responses for each question and the demographic groups. This tested for homogeneity in the distribution of the Likert responses among the different demographic groups [54-56]. For this test, we removed any demographic group with less than 25 total responses to remove groups with less than 5 expected responses per group [57]. After testing for group homogeneity but prior to running the chi-squared tests of independence, we pooled two groups of small categories. All analyses were performed in R [58] and are available on GitHub [59].

\section{Results}

\subsection{Gardens (Private Green Spaces)}

Of those respondents reporting that they had gardens $(n=712)$, the majority $(88.8 \%)$ spent time in their gardens. Both before and after the pandemic, respondents were most likely to spend time with their families in their gardens. After the pandemic, respondents were significantly less likely to spend time with friends, children, or with their neighbors (Figure 3).

\section{Who do respondents spend time with in their garden?}

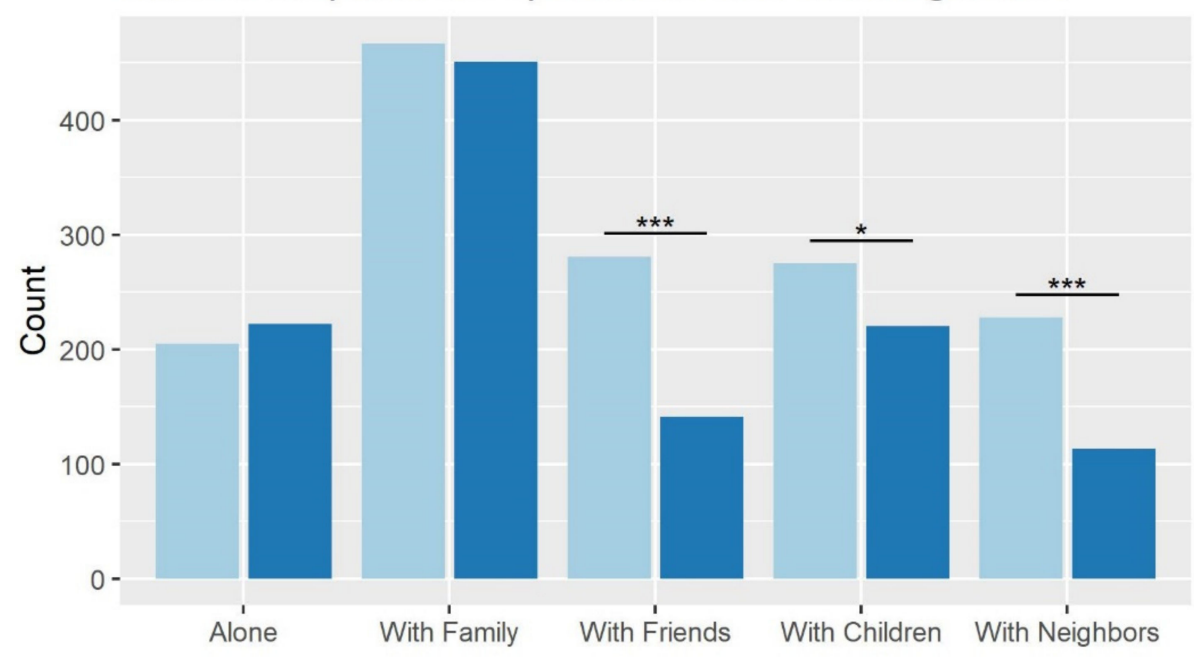

Before the pandemic After the pandemic occurred

Figure 3. Respondents spending time alone or with key social ties before and after the pandemic. No significant change was observed in the number of respondents spending time alone or with family; however, respondents were significantly less likely to spend time with friends, neighbors, or children after the pandemic. ${ }^{*} p \leq 0.05 ;{ }^{* * *} p \leq 0.001$.

Respondents engaged in all the queried garden activities, with the most common being relaxing in the garden $(n=630)$ and the least common harvesting bird nests ( $n=85$; Supplemental Information S3). Respondents participated in all passive and interactive activities in gardens more often after the beginning of the COVID-19 pandemic. Of the exploitative activities, tending livestock was significantly more common after the pandemic, while searching for bird nests and hunting was not (Figure 4). 
Do respondents perform activities in gardens less or more often after the COVID-19 pandemic?

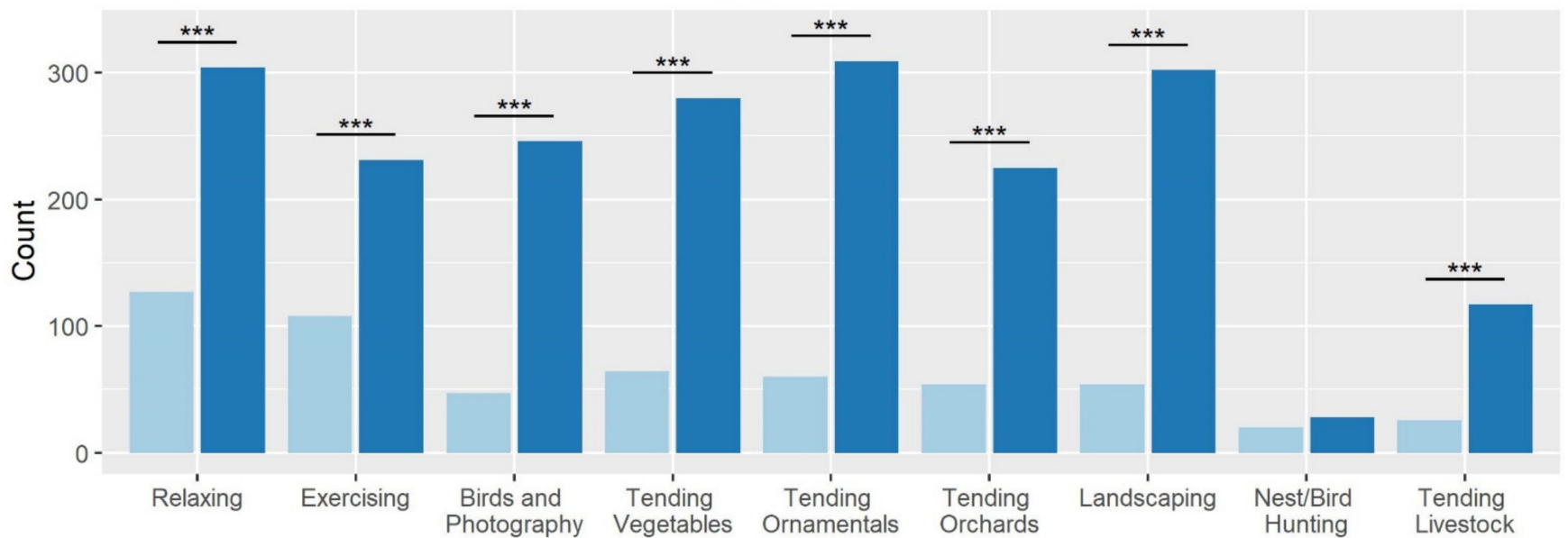

Less often

More often

Figure 4. Count of respondents participating in different activities in their garden less often or more often after the beginning of the COVID-19 pandemic. Passive activities include relaxing, exercising, and birdwatching and photography. Interactive activities include tending vegetables, tending ornamentals, tending orchards (fruit trees), and other landscaping activities. Extractive activities include searching for bird nests, hunting, and tending livestock. ${ }^{* *} p \leq 0.001$.

After controlling for multiple tests, we found that few of the activity Likert responses were dependent on demographic variables; specifically, only tending orchards was dependent on the level of education (Supplemental Information S4). Post hoc tests suggest that respondents in the high school or less and diploma (associate degree or trade degree) groups differ significantly from the bachelor or masters or more groups.

\subsection{Urban Parks (Public Green Spaces)}

Over half of our respondents $(n=737 ; 57.7 \%)$ visited urban parks. Respondents were more likely to visit urban parks alone after the pandemic, and less likely to visit parks with family, friends, children, or their neighbors (Figure 5).

Similarly, respondents' methods of travel to urban parks shifted away from methods with proximity to non-family members, with bus and taxi travel significantly decreasing (Figure 6). Travelling by car was the most common method of travel both before $(n=489)$ and after $(n=443)$ the start of the pandemic, followed by walking $(n=317$ and $n=335$, respectively). Low levels of travel by biking are expected, as biking is uncommon in Palestine due to the rough topography and socio-cultural factors. The largest group of respondents traveled over $2 \mathrm{~km}$ to visit an urban park both before and after the pandemic, and there was no significant change in distance travelled (Supplemental Information S3). 
Who do respondents spend time with in urban parks?

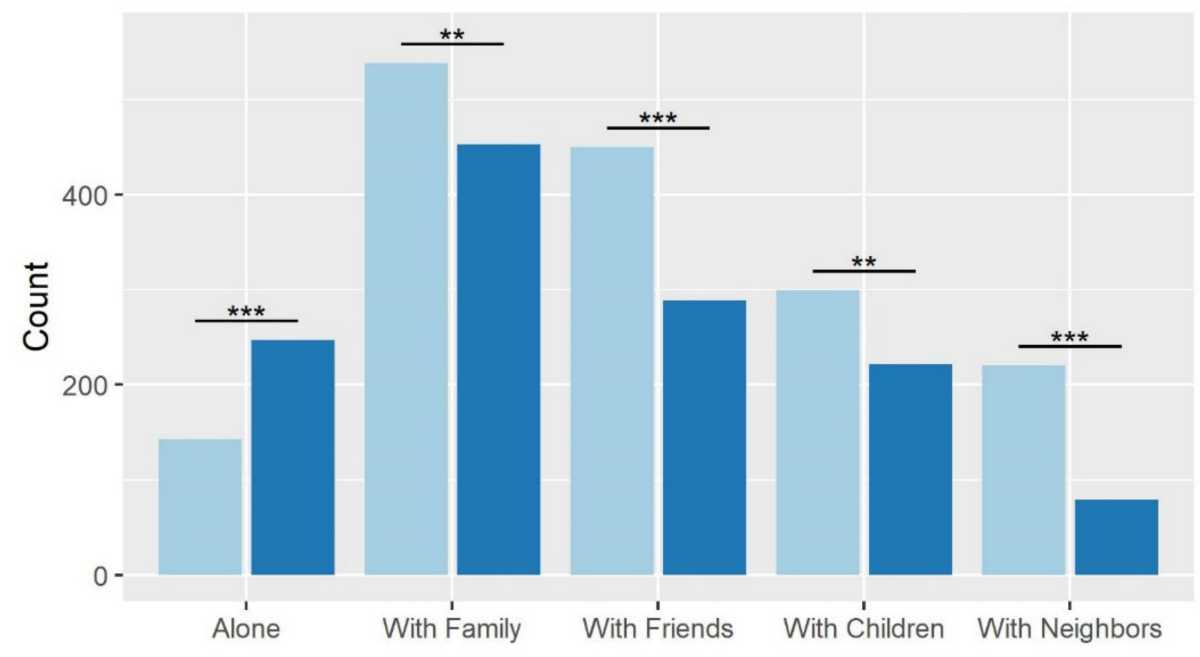

Before the pandemic

After the pandemic occurred

Figure 5. Respondents spending time alone, or with family, friends, children, or neighbors in urban parks before and after the onset of the COVID-19. Respondents spending time alone significantly increased, while all others decreased. ${ }^{* *} p \leq 0.01 ;{ }^{* * *} p \leq 0.001$.

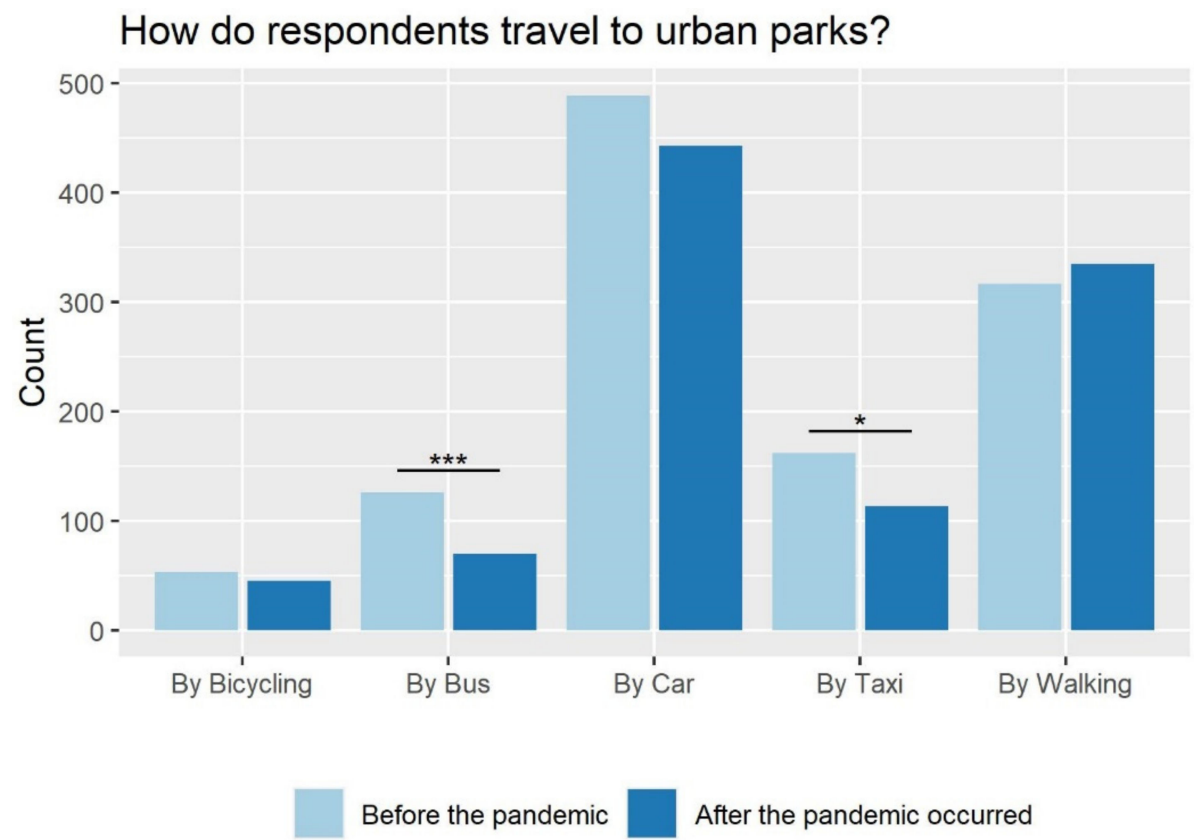

Figure 6. Respondents' methods of travelling to urban parks before and after the pandemic occurred. Significant decreases are seen for methods with proximity to non-family members. ${ }^{*} p \leq 0.05$; $* * * p \leq 0.001$.

The most common activity respondents participated in in urban parks was relaxing ( $n=695)$ and the least common was searching for nests and hunting $(n=145)$; respondents participated in both activities less often after the pandemic (Figure 7).

After controlling for multiple tests, demographic variables were generally independent from Likert responses. The exception was marital status, where respondents who were married were more likely to report that they participated in relaxing/socializing, bird watching/photography, or searching for nests and hunting activities in parks much less or less often after the COVID-19 pandemic (Supplemental Information S3). 


\section{Do respondents perform activities in urban parks less or more often after the COVID-19 pandemic?}

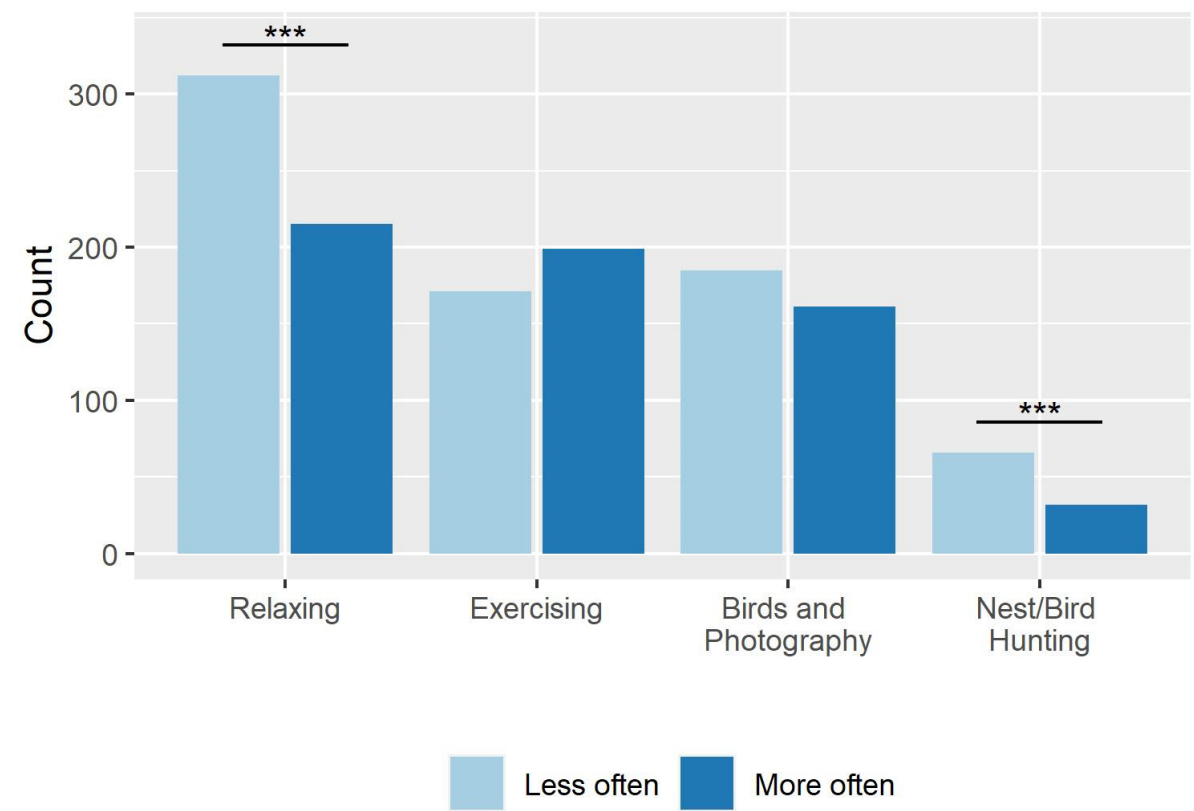

Figure 7. Count of respondents participating in activities in urban parks less often or more often after the beginning of the COVID-19 pandemic. Passive activities include relaxing, exercising, and birdwatching and photography. Nest searching and hunting is an extractive activity. ${ }^{* *} p \leq 0.001$.

\subsection{Natural Areas}

Most of our respondents visited natural areas $(n=959 ; 75.1 \%)$. Mirroring the results from urban parks, respondents were significantly more likely to visit natural areas alone and less likely to visit natural areas with family, friends, children, or neighbors after the pandemic occurred (Figure 8).

Who do respondents spend time with in natural areas?

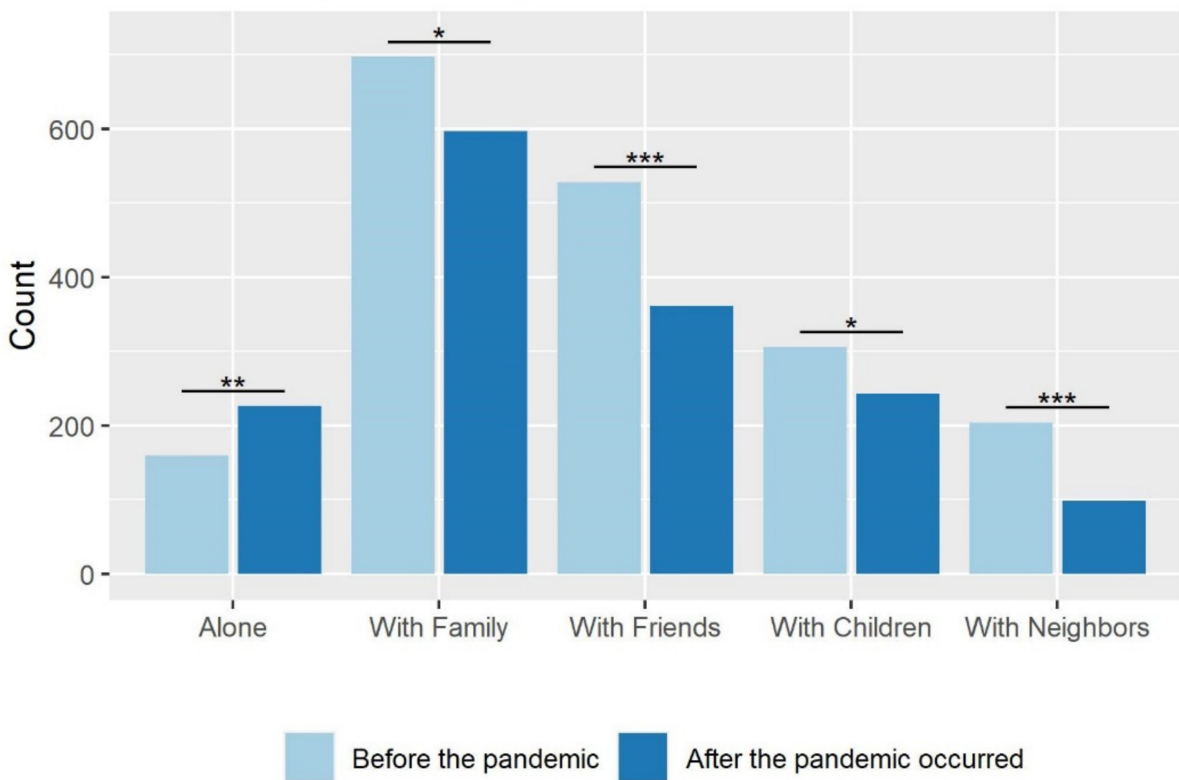

Figure 8. Respondents spending time alone, or with family, friends, children, or neighbors in natural areas before and after the onset of the COVID-19 pandemic. Respondents spending time alone significantly increased, while all others decreased. ${ }^{*} p \leq 0.05 ;{ }^{* *} p \leq 0.01 ;{ }^{* * *} p \leq 0.001$. 
Respondents were also less likely to travel to natural areas via bus or taxi, and the most common ways of travelling to natural areas were by car and on foot (Figure 9). The largest group of respondents traveled over $4 \mathrm{~km}$ to visit natural areas, and there was no change in distance traveled after the pandemic (Supplemental Information S3).

How do respondents travel to natural areas?

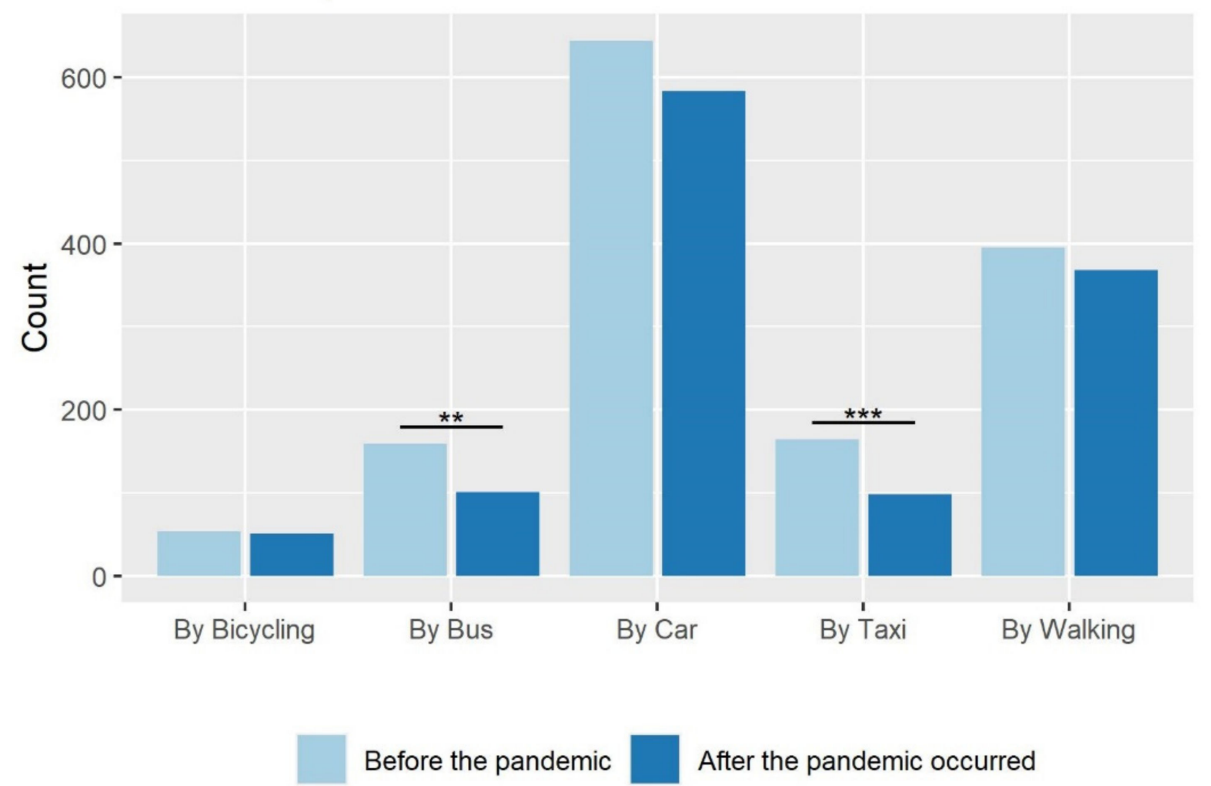

Figure 9. Respondents' methods of travelling to natural areas before and after the pandemic occurred. Significant decreases are seen for methods with proximity to non-family members. ${ }^{* *} p \leq 0.01 ; * * * 0 \leq 001$.

Passive activities, particularly relaxing/socializing, were the most common activities reported by respondents. There was no significant difference in the number of respondents reporting that they participated in activities less often versus more often after the pandemic (Figure 10). However, respondents reported participating in multiple interactive cultivation activities more often after the pandemic occurred, while respondents participated in some extractive activities less often after the pandemic. In the West Bank, natural open spaces might be public land that cannot be modified or cultivated, or might be private land that can be modified or cultivated. Landscaping activities in privately owned natural areas are often in service of agricultural purposes and include terracing.

Unlike activities in gardens and urban parks, the distribution of responses from multiple reported activities were dependent on respondents' demographic groups. Multiple passive appreciation questions, including relaxing/socializing, exercising, and bird watching/photography, along with searching for bird nests and hunting, were dependent on marital status, with married respondents more likely to report that they participated in these activities less often (Supplemental Information S4). Another passive activity, visiting historic sites, was dependent on whether respondents' post-COVID-19 income increased or decreased. Post hoc tests suggest that those with unchanged incomes were more likely to participate in this activity at an increased frequency than those without income or those whose income decreased. Relaxing and cultivating crops in natural areas was dependent on housing status, with respondents living in apartments reporting that they participated in these activities much less or less often at greater rates than respondents living in houses. Cultivating crops and tending to orchards (olives and other fruiting trees) was dependent on the type of location in which respondents lived. Post hoc tests revealed that respondents living in villages (more rural) significantly differed from those living in cities for cultivating crops and those in both cities and towns (more urban) for tending orchards. Respondents living in villages were more likely to report that they participated in these activities more often or much more often after the pandemic compared with their more 
urban counterparts. Finally, tending to orchards was also dependent on level of education, with post hoc tests revealing multiple differences between almost all education levels (Supplemental Information S3).

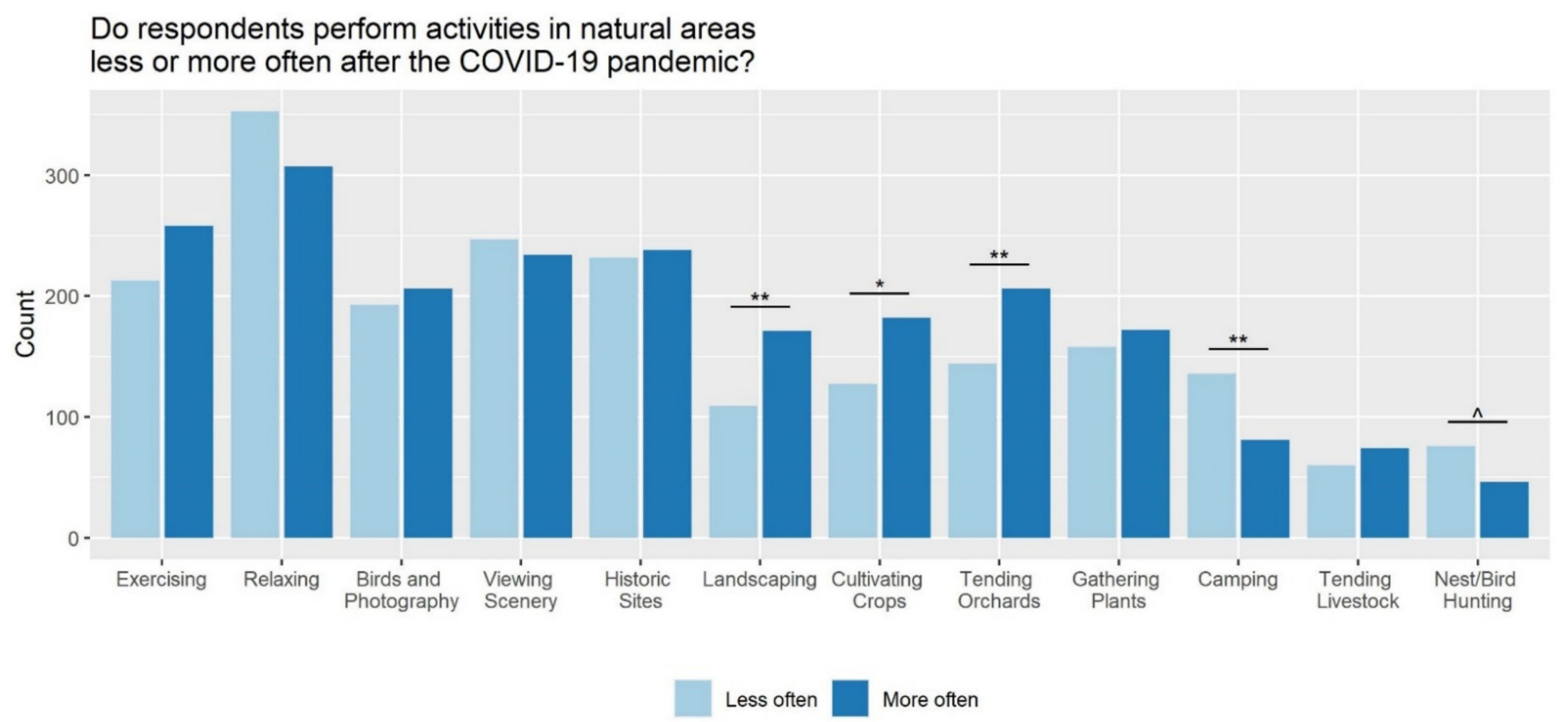

Figure 10. Count of respondents participating in different activities in natural areas less often or more often after the beginning of the COVID-19 pandemic. Passive activities include relaxing, exercising, birdwatching and photography, viewing scenery, and visiting historic sites. Interactive activities include landscaping, cultivating crops, and tending orchards (fruit trees). Extractive activities include gathering plants, camping, tending livestock, and searching for bird nests and hunting. ^ $p \leq 0.1{ }^{*} p \leq 0.05 ;{ }^{* *} p \leq 0.01$.

\section{Discussion}

We found that lockdown had a profound effect on residents' visitation to and activities in all types of green spaces, including gardens, urban parks, and natural areas. While patterns of change with visitation were similar across all three types of green space, the activities that respondents participated in following the pandemic did change differently across the three types.

\subsection{Impacts of Lockdown on Visitation}

Across all three types of green space, we found that residents were generally more likely to spend time alone and less likely to spend time with friends, family, and neighbors in these spaces. These results follow the lockdowns put into effect in the West Bank, which restricted residents from visiting or gathering with other households. However, these restrictions likely impacted the social ties and mental health of residents.

For example, in Palestine, a home garden is a place of socializing and gathering with others: family, friends and neighbors. One key socio-cultural aspect of having a garden in Palestine, like in other developing countries $[60,61]$, is to spend time with family and friends on a daily basis. Spending less time with these groups is a good indicator of social isolation. While this minimizes the possibility of being infected, as in other regions, it likely has a negative impact on health, well-being, and quality of life $[14,15,62]$ as socializing in these spaces is important for Palestinians.

Similarly, urban parks play an essential role in improving quality of life due to their social functions in increasing family ties and providing a safe space for children to play both in developing countries [63] and developed countries [64,65]. Our results suggest that the pandemic and associated lockdown have significantly minimized these benefits in Palestine. While there were fewer restrictions on visiting nature in Palestine during 
lockdown - in fact, there were unofficial calls from local health directors to residents to visit nature-these restrictions significantly reduced visits with important social groups.

Though detrimental to socialization, the lower rates of visitation in groups may have benefited wildlife. In other areas, the fact that lower rates of human disturbance of wildlife contributing to increased wildlife populations is considered one of the positive effects of the COVID-19 lockdown [6,9]. However, long-term conservation research and conservation practices, such as controlling invasive species and restoring degraded habitat, have been negatively affected in national parks in the US [5]. As there are no studies describing the effects of the pandemic on conservation practices in developing countries, it is not yet known how the COVID-19 lockdown influenced conservation in Palestine, and additional research is needed in light of our results.

Transportation patterns of respondents to urban parks and natural areas changed in very similar ways, as fewer residents used modes of transportation operated by others (busses and taxis), reducing the chance of infection. These methods of transportation were strictly controlled during lockdown, while self-operated modes of transportation (bicycle, car, and walking) were not. This result is highly dependent on the level of movement restriction applied in the country, as seen in the inconsistent findings from different developing countries. In Bangladesh, for instance, people continued to prefer busses as their mode of transport during the pandemic despite the health risks [66], while in India, reliance on busses dropped significantly after the pandemic [67].

The high and sustained use of cars is logical, as the largest groups of visitors traveled over $2 \mathrm{~km}$ to visit urban parks and over $4 \mathrm{~km}$ to visit natural areas. This distance did not decrease during the pandemic as it did in other studies [68], which may be due to the limited number of urban parks and natural areas available in Palestine for residents to visit. The reduced use of internal combustion engines in other studies was linked with decreases in pollutant emissions, including $\mathrm{PM}_{10}, \mathrm{PM}_{2.5}, \mathrm{NO}_{2}$, and $\mathrm{CO}_{2}$, as well as less noise pollution $[4,6,9]$. Our study focused solely on recreational trips, not work trips, so the impact on emissions is uncertain; however, this is a good area for further research.

\subsection{Changes in Activities following the COVID-19 Pandemic}

Overall, we found important differences between green space types and between activity types (Table 2). First, participation in activities of passive appreciation of nature increased for home gardens but decreased in urban parks and natural areas. Second, interactive activities, including cultivation activities, increased for all areas. Finally, extractive activities stayed the same or decreased for all areas.

Participation in passive activities drastically increased in private gardens following the COVID-19 pandemic in Palestine (Figure 4; Table 2). Palestine's movement restriction policies, stay-home order and social distancing forced people to spend more time in their gardens and do more activities. The changes in activity levels we observed are likely to have supported respondent's mental health during the lockdown, as home gardens have long been known to increase residents' well-being [13,19,20,22]. A recent metanalysis found that this holds across many different countries, even accounting for publication bias [69]. During the COVID-19 pandemic, researchers found that passive activities such as exercising, getting fresh air, and being connected to the earth increased due to the increased amount of time spent at home, and had positive mental and spiritual effects in Australia [18]. Similarly, in Italy, researchers found that respondents' participation in gardening activities was related to lower psychopathological distress associated with the COVID-19 pandemic [13].

In sharp contrast with home gardens, participation in passive activities in urban parks and native areas either significantly decreased (relaxing in urban parks) or showed no change (all others). These results contrast with findings in other locations, which found the increased use of urban parks as long as they remained open (e.g., [3]). For urban parks in Palestine, there are two likely drivers; first, the number of people allowed in these areas was decreased during lockdown. Second, the shops and amusement activities present in 
urban parks were closed, removing a major opportunity for people to visit and relax in these spaces.

Table 2. Different classes of activities that are common in Palestine and were used in this research. Green arrows indicate a significant increase, dark blue arrows indicate a significant decrease, and light blue arrows indicate no significant difference.

\begin{tabular}{|c|c|c|c|c|}
\hline & & Home Garden & Urban Park & Natural Area \\
\hline \multirow{7}{*}{ 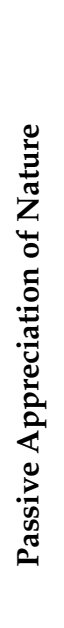 } & Exercising & & & \\
\hline & Relaxing, picnicking, socializing & & & \\
\hline & Watching wildlife, birding, and photography & & & \\
\hline & Viewing scenery & & & \\
\hline & Historic and natural site exploration & & & \\
\hline & Walking to green spaces & & & \\
\hline & Biking to green spaces & & & \\
\hline \multirow{6}{*}{ 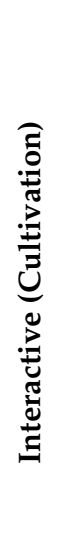 } & Tending vegetables & & & \\
\hline & Tending ornamentals & & & \\
\hline & Tending orchard & & & \\
\hline & Landscaping & & & \\
\hline & Cultivating crops & & & \\
\hline & Tending livestock & & & \\
\hline \multirow{6}{*}{ 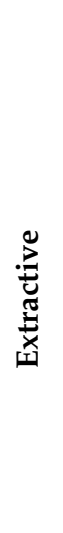 } & Gathering plants & & & \\
\hline & Nest searching and hunting & & & \\
\hline & Group camping & & & \\
\hline & Taxiing to green spaces & & & \\
\hline & Driving to green spaces & & & \\
\hline & Bussing to green spaces & & & \\
\hline
\end{tabular}

In natural areas, our results match the lower interest and visitation rates seen in national parks globally [12,45], but not the increased rate of use of the countryside for walks, hikes, and other activities [38,39,43]. Souza et al. (2021) found a significant difference 
between countries with increasing visitation like Finland, where national parks are largely visited by citizens, and countries with decreasing visitation like South Africa, where national parks largely attract international visitors. In Palestine, these passive activities were not exempt from movement restrictions, so these COVID-19 restrictions likely blunted any increase in passive activities that may have otherwise been seen. Respondents who were used to visiting nature before the pandemic for exercising, relaxing, photography and other passive activities kept their habits after the pandemic with no significant changes.

The contrast between increasing participation in passive activities in gardens with patterns of decreasing or no change in participation in urban parks and natural areas is a result not seen in other papers. This highlights the need for future research to consider patterns of change caused by COVID-19 across multiple types of green space.

Respondents' participation in agriculture, specifically tending crops and orchards, generally increased following the pandemic across green space types (Table 2). In home gardens, our results agree with other research findings that residents' interactive relationship with their gardens, including growing food and raising livestock, increased during the pandemic $[18,24,25,39]$. For example, recent research found that $51 \%$ of the respondents grow at least one type of vegetable or fruit, and $17 \%$ of those have started growing food in their gardens during the COVID-19 pandemic [23]. For natural areas, in Palestine during the lockdown, agricultural areas and the roads leading to farms experienced less movement restrictions and farmers and landowners were allowed to access their lands in natural areas and the countryside. These efforts were likely beneficial for food supply and food security, with efforts in natural areas at a larger scale than home gardens or community gardens $[19,23,24,26]$.

Participation in extractive activities decreased or had no significant change across green space types (Table 2). Participation in camping activities decreased following the COVID-19 pandemic, agreeing with other research [39]. In Palestine, camping sites are usually available in protected sections of natural areas that require travelling long distances; camping trips are usually organized by companies specializing in these types of expeditions. These areas are largely under the control of Israeli Occupation Forces, who closed them completely during the pandemic. Like other types of natural touristic uses, large groups of people are usually involved in camping activities, so reduced camping participation may have reduced disruption to wildlife and the destruction of wild plants as well as the negative impacts on soils and vegetation [70-72]. However, these trips provide contact with nature and a special form of socializing and recreation for Palestinians. In addition, like other touristic sectors in Palestine, the companies running these trips and their employees have been suffering from the negative economic consequences of declining demands for nature tourism [73]. These results agree with other research from developing and developed countries, which has found that the pandemic and lockdown have had a negative economic impact on protected areas due to lower visitation. Several countries-including Brazil, Costa Rica, Ecuador, Namibia, Indonesia, the United States and Canada-experienced a dramatic decrease in visitors to protected areas, which had negative economic consequences for recreation sector employees (Germany was the sole exception) [12,74]. In Africa, approximately $90 \%$ of safari tour operators surveyed experienced an over $75 \%$ decline in bookings through February of 2021, and while bookings have improved slightly, the majority of operators are still experiencing severe declines in bookings and increased cancellations [75]. In Palestine, workers lost their jobs and goods, service suppliers lost sales, and tourism businesses totally or partially closed [73].

Notably, participation in searching for nests and hunting showed no change (gardens) or decreased significantly (urban parks and natural areas). Less nest poaching and hunting are certainly good for wildlife in Palestine because the country suffers from uncontrolled intensive hunting which is usually considered a major barrier to any progress in wildlife conservation and protection [76-79]. In Palestine, eggs are frequently taken from the nests of native birds, especially chukar partridge (Alectoris chukar), either for fun as a traditional habit or for commercial purposes. Some people collect chukars' eggs as 
a seasonal business. They collect eggs in the breeding season and incubate them in artificial incubators and sell a pair of birds for USD 50-70. In urban parks and natural areas, the decline in nest poaching may be because the peak of the chukar breeding season is between March and the end of May. During this period in 2020, the lockdown and the movement restrictions were very strict. This prevented the poachers from reaching breeding areas in remote mountains and hills. Furthermore, hunting in Palestine is usually a group activity and requires commuting long distances, both of which were hindered by the lockdown. Additionally, stores selling hunting equipment and the difficulty importing goods made obtaining hunting materials and tools difficult. Reduced poaching during the COVID-19 crisis was also seen across multiple developing and developed countries, including South Africa, Brazil, Costa Rica, Ecuador, Indonesia, the United States and Canada [12,80]. However, increases in poaching were also seen in several developing countries in Asia and Africa, due to reduced conservation funding, increased conservation threats, and impaired conservation operations [74,81].

\subsection{Did Demographics Influence Changes in Activities?}

For gardens and urban parks, demographics generally did not explain changes in activity participation rates after the pandemic. Comparisons of these results with other studies was difficult; most other studies examined how demographics impacted visitation rates instead of activity participation [34,37,40,52,82]. Demographics have long been known to impact the usage of space and may lead to inequities in access to green space [83-85]. However, comparative studies, including those examining visitation rates, all found that at least one and frequently more demographic variables had a significant influence on green space visitation rates or activity types (see Supplemental Information S4 for a complete table; $[34,37,40,52,82])$. For example, one study [37] found women and older residents spent less time in green spaces, while another [82] found that gender, age, income, and number of children was associated with access to and use of urban green spaces. The paucity of significant variables found in our study may suggest that COVID-19-related changes in behavior in these green spaces may have equally impacted groups, or it may suggest that existing inequities were maintained.

However, it is worth noting that the findings of existing research are not consistent. For example, while one study [39] found that women in the Northeast US increased their gardening activities and increased walking, hiking, relaxing, and wildlife watching activities, other research studies found the opposite. For example, [37] found that women spent less time in green spaces following the onset of the COVID-19 pandemic, [52] found that women made fewer recreational trips, and [82] found that women have less access to and use of urban green spaces.

In contrast, in natural areas, we found multiple passive activities (including relaxing/socializing, exercising, and bird watching/photography) and searching for bird nests and hunting were dependent on marital status. It is possible that single respondents had more freedom to move about than married respondents, who may have had greater household and childcare responsibilities, although in Japan families with children were more likely to visit green spaces [82]. Other passive activities were dependent on changes in income (visiting historic sites) and housing status (relaxing/socializing). Further, interactive cultivation activities were dependent on housing status (cultivating crops), type of location (cultivating crops, tending to orchards), and level of education (tending to orchards). Most existing research on human-nature interactions in natural areas focus on the impact of the pandemic on, e.g., pollution, wildlife, and conservation activities, without focusing on who visits, how often they visit, and what activities they participate in $[4,6,9,11,12]$. Our study contributes to the literature by examining how reported participation in activities was dependent on demographic groups. Additional research, including in diverse geographical, biophysical, environmental, and cultural contexts, is needed, especially in developing countries due to the lack of such detailed studies. Such studies will contribute 
to addressing the noted inconsistencies in gardens and urban green spaces and the lack of comparable studies in natural areas, and in enriching the literature of developing countries.

\section{Conclusions}

The COVID-19 pandemic altered multiple aspects of how residents of Palestine interact with green spaces, specifically home gardens, urban parks, and natural areas. Across all types of green space, residents spent less time with family and friends and more time alone, pointing to possible concerns about mental health [15]. Residents also traveled to urban parks and natural areas less frequently using modes of transportation operated by others (busses and taxis), reducing the chance of infection. In addition, we found key differences in respondents' participation in activities both between green space types and between activity types (Table 2). Participation in passive appreciation of nature activities increased for home gardens but decreased in urban parks and natural areas. Interactive activities, including cultivation activities, increased for all areas, while extractive activities stayed the same or decreased for all areas. Only in natural areas did respondent's demographics explain changes in activity participation rates after the pandemic.

Our results highlight the importance of looking across different types of natural spaces, as patterns differ between types. For example, without asking respondents about their activities in home gardens, urban parks, and natural areas, we would not have been able to discern the differences in participation in passive appreciation of nature activities between the three types of natural spaces (Table 2). Examining only one type of natural spaces (e.g., only parks) or one type of activity (e.g., only gardening) would have missed important patterns in residents' altered behavior patterns. Thus, our framework may be valuable to other researchers attempting to understand changes in human-nature interactions due to the COVID-19 pandemic. These patterns provide insight into residents' responses to pandemic lockdowns that may have implications for mental health, public health, and urban planning, and should be studied further.

Additionally, our findings regarding differences between demographic groups and changes in activity patterns revealed differences across marital status and education level, but not across economic strata as measured by salary. Examining both access and use for nature-based activities in green spaces across demographic groups is important for urban designers and planners to ensure equitable access to these important resources. Future research, along with planning for public green spaces, should consider both access and use. Our research and others' research focusing on demographic differences in changes to residents' use of green space during the COVID-19 pandemic are an important step in this process.

Unlike other research that has been conducted within a Western context, our research was conducted in the West Bank of Palestine, which is both an area of geopolitical instability and a developing country. Despite Palestine's unique socio-economic and cultural context, our findings regarding respondents' changes in activity due to the COVID-19 pandemic agreed in many ways with trends seen in other research (e.g., [18,39]). In this way, the impact of the pandemic and particularly lockdowns due to the pandemic have been so strong as to reduce differences between some contexts.

Whether the patterns we observed hold across other locations and points in time is an important unanswered question for future study. We captured activity changes at one point in time approximately 15 months after the onset of lockdown restrictions, and we do not yet know whether these changes in activity will persist through the ongoing COVID19 pandemic. Understanding the dynamics of residents' participation in human-nature activities may drive changes in how we view gardens, green spaces, and natural areas. Urban planners and ecologists have long understood the importance of these spaces due to the important ecosystem services they provide. For residents to continue to enjoy these ecosystem services, such as mental health support, while preventing disease spread, the current layout of parks and natural areas may need to be revised. 
Supplementary Materials: The following are available online at https:/ / www.mdpi.com/article/10 .3390/su132413831/s1, S1: Survey instrument, S2: Demographic comparison, S3: Detailed results, S4: Activity question statistical tests.

Author Contributions: Conceptualization, E.B.D. and K.D.; methodology, E.B.D. and K.D.; formal analysis, K.D.; investigation, E.B.D. and K.D.; data curation, E.B.D.; writing-original draft preparation, E.B.D. and K.D.; writing-review and editing, E.B.D. and K.D.; visualization, K.D.; project administration, E.B.D. and K.D.; supervision, E.B.D. All authors have read and agreed to the published version of the manuscript.

Funding: This research received no external funding.

Institutional Review Board Statement: Ethical review and approval were waived for this study, as our research did not include patients, medical experiments, or personal health information.

Informed Consent Statement: Informed consent was obtained from all subjects involved in the study.

Data Availability Statement: The data and code used to create the results presented in this study are openly available in GitHub online at https://github.com/kdyson/nature_covid19 (accessed on 11 December 2021), DOI: 10.5281 /zenodo.5766241.

Acknowledgments: The authors thank Abdallah Alomari and his team in the National Agricultural Research Center for reviewing our survey instrument. They also thank the Open Society Foundation for the financial and logistic support they offered for the first author to visit the University of Washington while conducting this research, and finally Marina Alberti, Tracy Fuentes, and the Urban Ecology Research Lab for valuable feedback on an earlier version of this manuscript.

Conflicts of Interest: The authors declare no conflict of interest.

\section{References}

1. Samuelsson, K.; Barthel, S.; Colding, J.; Macassa, G.; Giusti, M. Urban nature as a source of resilience during social distancing amidst the coronavirus pandemic. OSF Prepr. 2020. [CrossRef]

2. Geng, D.C.; Innes, J.; Wu, W.; Wang, G. Impacts of COVID-19 pandemic on urban park visitation: A global analysis. J. For. Res. 2021, 32, 553-567. [CrossRef] [PubMed]

3. Volenec, Z.M.; Abraham, J.O.; Becker, A.D.; Dobson, A.P. Public parks and the pandemic: How park usage has been affected by COVID-19 policies. PLoS ONE 2021, 16, e0251799. [CrossRef] [PubMed]

4. Bar, H. COVID-19 lockdown: Animal life, ecosystem and atmospheric environment. Environ. Dev. Sustain. 2021, 23, 8161-8178. [CrossRef] [PubMed]

5. Miller-Rushing, A.J.; Athearn, N.; Blackford, T.; Brigham, C.; Cohen, L.; Cole-Will, R.; Edgar, T.; Ellwood, E.R.; Fisichelli, N.; Pritz, C.F.; et al. COVID-19 pandemic impacts on conservation research, management, and public engagement in US national parks. Biol. Conserv. 2021, 257, 109038. [CrossRef] [PubMed]

6. Sharma, P.; Kaur, M.; Narwal, G. Other side of the COVID-19 Pandemic: A review. Pharma. Innov. 2020, 9, 366-369. Available online: https:/ / edition.cnn.com/2020/03/01/world/nasa-china- (accessed on 19 August 2021).

7. Nienhuis, C.P.; Lesser, I.A. The Impact of COVID-19 on Women's Physical Activity Behavior and Mental Well-Being. Int. J. Environ. Res. Public Health 2020, 17, 9036. [CrossRef]

8. Zambrano-Monserrate, M.A.; Ruano, M.A.; Sanchez-Alcalde, L. Indirect effects of COVID-19 on the environment. Sci. Total. Environ. 2020, 728, 138813. [CrossRef]

9. Chitra, J.; Rajendran, S.M.; Jeba Mercy, J.; Jeyakanthan, J. Impact of covid-19 lockdown in tamil nadu: Benefits and challenges on environment perspective. Indian J. Biochem. Biophys. 2020, 57, 370-381.

10. The Guardian. Silence Is Golden for Whales as Lockdown Reduces Ocean Noise; The Guardian: London, UK, 2020; pp. 1-5.

11. Gordo, O.; Brotons, L.; Herrando, S.; Gargallo, G. Rapid behavioural response of urban birds to COVID-19 lockdown. Proc. R. Soc. B Boil. Sci. 2021, 288, 20202513. [CrossRef]

12. Spenceley, A.; McCool, S.; Newsome, D.; Báez, A.; Barborak, J.R.; Blye, C.-J.; Bricker, K.; Cahyadi, H.S.; Corrigan, K.; Halpenny, E.; et al. Tourism in protected and conserved areas amid the COVID-19 pandemic. Parks 2021, 27, 103-118. [CrossRef]

13. Theodorou, A.; Panno, A.; Carrus, G.; Carbone, G.A.; Massullo, C.; Imperatori, C. Stay home, stay safe, stay green: The role of gardening activities on mental health during the Covid-19 home confinement. Urban For. Urban Green. 2021, 61, 127091. [CrossRef]

14. Hawkley, L.C.; Cacioppo, J.T. Loneliness Matters: A Theoretical and Empirical Review of Consequences and Mechanisms. Ann. Behav. Med. 2010, 40, 218-227. [CrossRef] [PubMed]

15. Holt-Lunstad, J.; Smith, T.B.; Baker, M.; Harris, T.; Stephenson, D. Loneliness and Social Isolation as Risk Factors for Mortality: A Meta-Analytic Review. Perspect. Psychol. Sci. 2015, 10, 227-237. [CrossRef] 
16. Brooks, S.K.; Webster, R.K.; Smith, L.E.; Woodland, L.; Wessely, S.; Greenberg, N.; Rubin, G.J. The psychological impact of quarantine and how to reduce it: Rapid review of the evidence. Lancet 2020, 395, 912-920. [CrossRef]

17. McCunn, L.J. The importance of nature to city living during the COVID-19 pandemic: Considerations and goals from environmental psychology. Cities Health 2020, 1-4. [CrossRef]

18. Katz, H. Crisis Gardening: Addressing Barriers to Home Gardening during the COVID-19 Pandemic; Paper Knowledge. Toward a Media History of Documents; The Austrailan Food Network: Melbourne, Australia, 2020.

19. Sofo, A.; Sofo, A. Correction to: Converting Home Spaces into Food Gardens at the Time of Covid-19 Quarantine: All the Benefits of Plants in this Difficult and Unprecedented Period (Hum. Ecol. 2020, 48, 2, 131-139, doi: 10.1007/s10745-020-00147-3). Hum. Ecol. 2020, 48, 141. [CrossRef]

20. Dunnett, N.; Qasim, M. Perceived Benefits to Human Well-being of Urban Gardens. HortTechnology 2000, 10, 40-45. [CrossRef]

21. Kellett, J.E. The private garden in England and Wales. Landsc. Plan. 1982, 9, 105-123. [CrossRef]

22. Mullins, L.; Charlebois, S.; Finch, E.; Music, J. Home Food Gardening in Canada in Response to the COVID-19 Pandemic. Sustainability 2021, 13, 3056. [CrossRef]

23. Corley, J.; Okely, J.A.; Taylor, A.M.; Page, D.; Welstead, M.; Skarabela, B.; Redmond, P.; Cox, S.R.; Russ, T.C. Home garden use during COVID-19: Associations with physical and mental wellbeing in older adults. J. Environ. Psychol. 2021, 73, 101545. [CrossRef]

24. Mejia, A.; Bhattacharya, M.; Nigon-Crowley, A.; Kirkpatrick, K.; Katoch, C. Community gardening during times of crisis: Recommendations for community-engaged dialogue, research, and praxis. J. Agric. Food Syst. Community Dev. 2020, 10, 1-7. [CrossRef]

25. Oliver, C. Returning to 'The Good Life'? Chickens and Chicken-keeping during Covid-19 in Britain. Anim. Stud. J. 2021, 10, 114-139. [CrossRef]

26. Nicola, S.; Ferrante, A.; Cocetta, G.; Bulgari, R.; Nicoletto, C.; Sambo, P.; Ertani, A. Food Supply and Urban Gar-dening in the Time of Covid-19. Bull. UASVM Hortic. 2020, 77, 141-144.

27. Lerman, S.B.; Narango, D.L.; Avolio, M.L.; Bratt, A.R.; Engebretson, J.M.; Groffman, P.M.; Hall, S.J.; Heffernan, J.B.; Hobbie, S.E.; Larson, K.L.; et al. Residential yard management and landscape cover affect urban bird community diversity across the continental USA. Ecol. Appl. 2021, 31, e02455. [CrossRef] [PubMed]

28. Kennedy, P.L.; Fontaine, J.B.; Hobbs, R.J.; Johnson, T.; Boyle, R.; Lueders, A.S. Do novel ecosystems provide habitat value for wildlife? Revisiting the physiognomy vs. floristics debate. Ecosphere 2018, 9, e02172. [CrossRef]

29. Van Helden, B.E.; Close, P.G.; Stewart, B.A.; Speldewinde, P.C.; Comer, S.J. An underrated habitat: Residential gardens support similar mammal assemblages to urban remnant vegetation. Biol. Conserv. 2020, 250, 108760. [CrossRef]

30. Rocha, E.A.; Souza EN, F.; Bleakley LA, D.; Burley, C.; Mott, J.L.; Rue-Glutting, G.; Fellowes, M.D.E. Influ-ence of urbanisation and garden plants on the diversity and abundance of aphids and their ladybird and hoverfly predators. Eur. J. Entomol. 2018, 115, 140-149. [CrossRef]

31. Majewska, A.A.; Altizer, S. Planting gardens to support insect pollinators. Conserv. Biol. 2020, 34, 15-25. [CrossRef] [PubMed]

32. Kleinschroth, F.; Kowarik, I. COVID -19 crisis demonstrates the urgent need for urban greenspaces. Front. Ecol. Environ. 2020, 18, 318-319. [CrossRef] [PubMed]

33. Venter, Z.S.; Barton, D.N.; Gundersen, V.; Figari, H.; Nowell, M. Urban nature in a time of crisis: Recreational use of green space increases during the COVID-19 outbreak in Oslo, Norway. Environ. Res. Lett. 2020, 15, 104075. [CrossRef]

34. Rice, W.L.; Pan, B. Understanding changes in park visitation during the COVID-19 pandemic: A spatial application of big data. Wellbeing Space Soc. 2021, 2, 100037. [CrossRef]

35. Derks, J.; Giessen, L.; Winkel, G. COVID-19-induced visitor boom reveals the importance of forests as critical infrastructure. For. Policy Econ. 2020, 118, 102253. [CrossRef] [PubMed]

36. Miller, Z.D.; Freimund, W.; Dalenberg, D.; Vega, M. Observing COVID-19 related behaviors in a high visitor use area of Arches National Park. PLoS ONE 2021, 16, e0247315. [CrossRef] [PubMed]

37. Burnett, H.; Olsen, J.R.; Nicholls, N.; Mitchell, R. Change in time spent visiting and experiences of green space following restrictions on movement during the COVID-19 pandemic: A nationally representative cross-sectional study of UK adults. BMJ Open 2021, 11, e044067. [CrossRef]

38. Grima, N.; Corcoran, W.; Hill-James, C.; Langton, B.; Sommer, H.; Fisher, B. The importance of urban natural areas and urban ecosystem services during the COVID-19 pandemic. PLoS ONE 2020, 15, e0243344. [CrossRef] [PubMed]

39. Morse, J.W.; Gladkikh, T.M.; Hackenburg, D.M.; Gould, R.K. COVID-19 and human-nature relationships: Vermonters' activities in nature and associated nonmaterial values during the pandemic. PLoS ONE 2020, 15, e0243697. [CrossRef]

40. Xie, J.; Luo, S.; Furuya, K.; Sun, D. Urban Parks as Green Buffers During the COVID-19 Pandemic. Sustainability 2020, 12, 6751. [CrossRef]

41. Cheng, Y.D.; Farmer, J.R.; Dickinson, S.L.; Robeson, S.M.; Fischer, B.C.; Reynolds, H.L. Climate change impacts and urban green space adaptation efforts: Evidence from U.S. municipal parks and recreation departments. Urban Clim. 2021, 39, 100962. [CrossRef]

42. Haas WDe Hassink, J.; Stuiver, M. The Role of Urban Green Space in Promoting Inclusion: Experiences from the Netherlands. Front. Environ. Sci. 2021, 9, 1-11. [CrossRef] 
43. Hockenhull, J.; Squibb, K.; Cameron, A. How Has the COVID-19 Pandemic Affected the Way We Access and Interact with the Countryside and the Animals within It? Animals 2021, 11, 2281. [CrossRef]

44. Kupfer, J.A.; Li, Z.; Ning, H.; Huang, X. Using Mobile Device Data to Track the Effects of the COVID-19 Pandemic on Spatiotemporal Patterns of National Park Visitation. Sustainability 2021, 13, 9366. [CrossRef]

45. Souza, C.N.; Rodrigues, A.C.; Correia, R.A.; Normande, I.C.; Costa, H.C.D.M.; Guedes-Santos, J.; Malhado, A.C.; Carvalho, A.R.; Ladle, R.J. No visit, no interest: How COVID-19 has affected public interest in world's national parks. Biol. Conserv. 2021, 256, 109015. [CrossRef]

46. Craig, C.A. Camping, glamping, and coronavirus in the United States. Ann. Tour. Res. 2021, 89, 103071. [CrossRef] [PubMed]

47. PCBS. The Official Website of the Palestinian Central Bureau of Statistics-State of Palestine. 2021. Available online: https://www.pcbs.gov.ps/Portals/_Rainbow/Documents/\%D8\%A7\%D9\%84\%D9\%85\%D8\%AD\%D8\%A7\%D9\%81\%D8\%B8 \%D8\%A7\%D8\%AA\%20\%D8\%B9\%D8\%B1\%D8\%A8\%D9\%8A\%2097-2010.html (accessed on 21 July 2021).

48. PCBS. Municipalities Infrastructure Database of the West Bank and Gaza Strip; Palestinian Bureau of Statistics Publications: Ramallah, Palestine, 2017; Reference No. 4.3.6. Grant No.: CPS 1022 01Y.

49. Isaac, J.; AKhair, A.; Hilal, J.; Ghattas, R.; Hardee, P. Status of the Environment in the Occupied Palestinian Territory, A Human Rights-Based Approach; The Applied Research Institute Jerusalem (ARIJ): Bethlehem, Palestine, 2011.

50. Qumsiyeh, M.; Amro, Z. Nature Protection and Environmental Reserves in Palestine: Opportunities and Challenges. In The Seventh Palestinian Environmental Awareness and Education Conference Proceedings; The Environmental Education Center: Bethlehem, Palestine, 2016.

51. Nekolný, L.; Fialová, D. Attendance and Perceived Constraints to Attendance at Zoological Gardens during the Spring 2020 COVID-19 Re-Opening: The Czechia Case. J. Zool. Bot. Gard. 2021, 2, 234-249. [CrossRef]

52. Landry, C.E.; Bergstrom, J.; Salazar, J.; Turner, D. How Has the COVID-19 Pandemic Affected Outdoor Recreation in the U.S.? A Revealed Preference Approach. Appl. Econ. Perspect. Policy 2021, 43, 443-457. [CrossRef]

53. NapoleonCat. Official Website of NapoleonCat Social Media Analytics Platform. 2021. Available online: https://napoleoncat. com/stats / facebook-users-in-state_of_palestine/2021/01/ (accessed on 17 July 2021).

54. Boone, H.N.; Boone, D.A. Analyzing likert data. J. Ext. 2012, 50, 1-5.

55. Sullivan, G.M.; Artino, A.R., Jr. Analyzing and interpreting data from Likert-type scales. J. Grad. Med Educ. 2013, 5, 541-542. [CrossRef]

56. Norman, G. Likert scales, levels of measurement and the "laws" of statistics. Adv. Health Sci. Educ. 2010, 15, 625-632. [CrossRef]

57. McDonald, J.H. Handbook of Biological Statistics, 3rd ed.; Sparky House Publishing: Baltimore, MD, USA, 2014 ; pp. 86-89.

58. R Core Team. R: A language and environment for statistical computing. R Foundation for Statistical Computing, Vienna, Austria. 2021. Available online: https:/ / www.R-project.org/ (accessed on 13 December 2021).

59. Dyson, K.; Dawwas, E. Nature and Covid-19 (Version 1.0). 2021. Available online: https://github.com/kdyson/nature_covid19 (accessed on 13 December 2021).

60. Christie, M.E. Kitchenspace, Fiestas, and Cultural Reproduction in Mexican House-Lot Gardens. Geogr. Rev. 2004, 94, 368-390. [CrossRef]

61. WinklerPrins, A.M. House-Lot Gardens in Santarém, Pará, Brazil: Linking the Urban with the Rural. Urban Ecosyst. 2002, 6, 43-65. [CrossRef]

62. Kemperman, A.; Timmermans, H. Green spaces in the direct living environment and social contacts of the aging population. Landsc. Urban Plan. 2014, 129, 44-54. [CrossRef]

63. Bahriny, F.; Bell, S. Patterns of Urban Park Use and Their Relationship to Factors of Quality: A Case Study of Tehran, Iran. Sustainability 2020, 12, 1560. [CrossRef]

64. Chiesura, A. The role of urban parks for the sustainability of cities. Adv. Archit. Ser. 2004, 18, 335-344.

65. Kazmierczak, A. The contribution of local parks to neighbourhood social ties. Landsc. Urban Plan. 2013, 109, 31-44. [CrossRef]

66. Anwari, N.; Ahmed, M.T.; Islam, M.R.; Hadiuzzaman, M.; Amin, S. Exploring the travel behavior changes caused by the COVID-19 crisis: A case study for a developing country. Transp. Res. Interdiscip. Perspect. 2021, 9, 100334. [CrossRef]

67. Bhaduri, E.; Manoj, B.; Wadud, Z.; Goswami, A.K.; Choudhury, C.F. Modelling the effects of COVID-19 on travel mode choice behaviour in India. Transp. Res. Interdiscip. Perspect. 2020, 8, 100273. [CrossRef]

68. Ugolini, F.; Massetti, L.; Calaza-Martínez, P.; Cariñanos, P.; Dobbs, C.; Ostoić, S.K.; Marin, A.M.; Pearlmutter, D.; Saaroni, H.; Šaulienè, I.; et al. Effects of the COVID-19 pandemic on the use and perceptions of urban green space: An international exploratory study. Urban For. Urban Green. 2020, 56, 126888. [CrossRef]

69. Soga, M.; Gaston, K.J.; Yamaura, Y. Gardening is beneficial for health: A meta-analysis. Prev. Med. Rep. 2017, 5, 92-99. [CrossRef] [PubMed]

70. Cole, D.N.; Monz, C.A. Trampling disturbance of high-elevation vegetation, Wind River Mountains, Wyoming, USA. Arct. Antarct. Alp. Res. 2002, 34, 365-376. [CrossRef]

71. Cole, D.N. Impacts of hiking and camping on soils and vegetation: A review. Environ. Impacts Ecotourism 2004, 41, 41-60. [CrossRef]

72. Marzano, M.; Dandy, N. Recreationist behaviour in forests and the disturbance of wildlife. Biodivers. Conserv. 2012, 21, 2967-2986. [CrossRef] 
73. PCBS. The Palestinian Central Bureau of Statistics and the Ministry of Tourism and Antiquities Issue a Press Release on the Occasion of World Tourism Day. The Official Website of the Palestinian Central Bureau of Statistics-State of Palestine. 2020. Available online: https:/ /www.pcbs.gov.ps / postar.aspx?lang=ar\&ItemID=3816 (accessed on 21 July 2021).

74. Lindsey, P.; Allan, J.; Brehony, P.; Dickman, A.; Robson, A.; Begg, C.; Bhammar, H.; Blanken, L.; Breuer, T.; Fitzgerald, K.; et al. Conserving Africa's wildlife and wildlands through the COVID-19 crisis and beyond. Nat. Ecol. Evol. 2020, 4, 1300-1310. [CrossRef]

75. Beekwilder, J. The Impact of the Coronavirus Pandemic on the Safari Industry (November Update). 11 November 2021. Available online: https://www.safaribookings.com/blog/coronavirus-outbreak (accessed on 8 December 2021).

76. El Shaer, H.; Omer, K.; Albaradeiya, I.; Mahassneh, M.; Subah, I.; Dardounah, A.; Abu-Dayeh, K.; Ali-Shtayeh, M.S.; Jamous, R.; Al-Basha, W.; et al. State of Palestine Fifth National Report to the Convention on Biological Diversity; EQA: Ramallah, Palestine , 2015.

77. Beaumont, P. Palestine Mountain Gazelle Now Endangered, Say Scientists. The Guardian. 2015. Available online: https://www. theguardian.com/world/2015/sep/04/palestine-mountain-gazelle-now-endangered-say-scientists (accessed on 11 September 2021).

78. Hashem, B. The Rapid Degradation of Wadi Gaza. EcoMENA Echoing Ststainability in MENA Website. 2021. Available online: https:/ / www.ecomena.org/wadi-gaza/ (accessed on 11 September 2021).

79. Ballas, M. Warning of the Dangers of "Poaching" on Biodiversity in Palestine. Al-Ayam Newspaper Website. 2021. Available online: https: / / www.al-ayyam.ps/ar_page.php?id=146788e0y342329568Y146788e0 (accessed on 13 September 2021).

80. BBC. Rhino Poaching in South Africa Falls during Covid-19 Lockdown. BBC Website. 2021. Available online: https://www.bbc. com/news/world-africa-55889766 (accessed on 17 September 2021).

81. Koju, N.P.; Kandel, R.C.; Acharya, H.B.; Dhakal, B.K.; Bhuju, D.R. COVID-19 lockdown frees wildlife to roam but increases poaching threats in Nepal. Ecol. Evol. 2021, 11, 9198-9205. [CrossRef] [PubMed]

82. Uchiyama, Y.; Kohsaka, R. Access and Use of Green Areas during the COVID-19 Pandemic: Green Infrastructure Management in the "New Normal". Sustainability 2020, 12, 9842. [CrossRef]

83. Krenichyn, K. Women and physical activity in an urban park: Enrichment and support through an ethic of care. J. Environ. Psychol. 2004, 24, 117-130. [CrossRef]

84. Shores, K.A.; West, S.T. Rural and urban park visits and park-based physical activity. Prev. Med. 2010, 50, S13-S17. [CrossRef] [PubMed]

85. Arnold, M.L.; Shinew, K.J. The role of gender, race, and income on park use constraints. J. Park Recreat. Adm. 1998, 16, 39-56. 